Cite this: Phys. Chem. Chem. Phys., 2014, 16, 10503

Received 18th March 2014, Accepted 7th April 2014

DOI: $10.1039 / c 4 c p 01172 d$

www.rsc.org/pccp

\section{Thermochemical $\mathrm{CO}_{2}$ splitting via redox cycling of ceria reticulated foam structures with dual- scale porosities}

\author{
Philipp Furler, ${ }^{a}$ Jonathan Scheffe, ${ }^{a}$ Daniel Marxer, ${ }^{a}$ Michal Gorbar, ${ }^{b}$ \\ Alexander Bonk, ${ }^{\text {bc }}$ Ulrich Vogt ${ }^{\mathrm{bc}}$ and Aldo Steinfeld*ad
}

\begin{abstract}
Efficient heat transfer of concentrated solar energy and rapid chemical kinetics are desired characteristics of solar thermochemical redox cycles for splitting $\mathrm{CO}_{2}$. We have fabricated reticulated porous ceramic (foam-type) structures made of ceria with dual-scale porosity in the millimeter and micrometer ranges. The larger void size range, with $d_{\text {mean }}=2.5 \mathrm{~mm}$ and porosity $=0.76-0.82$, enables volumetric absorption of concentrated solar radiation for efficient heat transfer to the reaction site during endothermic reduction, while the smaller void size range within the struts, with $d_{\text {mean }}=10 \mu \mathrm{m}$ and strut porosity $=0-0.44$, increases the specific surface area for enhanced reaction kinetics during exothermic oxidation with $\mathrm{CO}_{2}$. Characterization is performed via mercury intrusion porosimetry, scanning electron microscopy, and thermogravimetric analysis (TGA). Samples are thermally reduced at $1773 \mathrm{~K}$ and subsequently oxidized with $\mathrm{CO}_{2}$ at temperatures in the range 873-1273 K. On average, $\mathrm{CO}$ production rates are ten times higher for samples with 0.44 strut porosity than for samples with non-porous struts. The oxidation rate scales with specific surface area and the apparent activation energy ranges from 90 to $135.7 \mathrm{~kJ} \mathrm{~mol}^{-1}$. Twenty consecutive redox cycles exhibited stable $\mathrm{CO}$ production yield per cycle. Testing of the dualscale RPC in a solar cavity-receiver exposed to high-flux thermal radiation $(3.8 \mathrm{~kW}$ radiative power at 3015 suns) corroborated the superior performance observed in the TGA, yielding a shorter cycle time and a mean solar-to-fuel energy conversion efficiency of $1.72 \%$.
\end{abstract}

\section{Introduction}

Solar thermochemical cycles based on two-step metal oxide redox reactions offer promising paths for solar-driven production of $\mathrm{H}_{2}$ and $\mathrm{CO}$ from $\mathrm{H}_{2} \mathrm{O}$ and $\mathrm{CO}_{2} \cdot{ }^{1-3}$ The resulting syngas mixture can be further converted to liquid hydrocarbon fuels via FischerTropsch or other catalytic processes. ${ }^{4}$ Among a variety of metal oxides used as intermediates for such two-step redox cycles, nonstoichiometric ceria $\left(\mathrm{CeO}_{2-\delta}\right)$ emerges as an attractive candidate because of its ability to rapidly conduct oxygen through its lattice ${ }^{5}$ and of its crystallographic stability over a wide range of oxidation states. $^{6,7}$ The cycle can be represented by:

$$
\text { High-T reduction : } \mathrm{CeO}_{2} \stackrel{+\Delta H}{\longrightarrow} \mathrm{CeO}_{2-\delta}+\frac{\delta}{2} \mathrm{O}_{2}
$$

\footnotetext{
${ }^{a}$ Department of Mechanical and Process Engineering, ETH Zurich, 8092 Zurich, Switzerland. E-mail: aldo.steinfeld@ethz.ch

${ }^{b}$ Laboratory for Hydrogen and Energy, Empa, 8600 Dübendorf, Switzerland

${ }^{c}$ Institute for Geo- and Life Sciences, Crystallography, Albert-Ludwigs-Universität Freiburg, 79085 Freiburg, Germany

${ }^{d}$ Solar Technology Laboratory, Paul Scherrer Institute, 5232 Villigen PSI, Switzerland
}

Low-T oxidation with $\mathrm{H}_{2} \mathrm{O}: \mathrm{CeO}_{2-\delta}+\delta \mathrm{H}_{2} \mathrm{O} \stackrel{-\Delta H}{\longrightarrow} \mathrm{CeO}_{2}+\delta \mathrm{H}_{2}$

Low-T oxidation with $\mathrm{CO}_{2}: \mathrm{CeO}_{2-\delta}+\delta \mathrm{CO}_{2} \stackrel{-\Delta H}{\longrightarrow} \mathrm{CeO}_{2}+\delta \mathrm{CO}$

In the first high-temperature endothermic (solar) step, eqn (1), ceria is thermally reduced to a nonstoichiometric state using concentrated solar radiation. In the second low-temperature (non-solar) exothermic step, eqn (2), ceria is re-oxidized with $\mathrm{H}_{2} \mathrm{O}$ and/or $\mathrm{CO}_{2}$ to produce $\mathrm{H}_{2}$ and/or CO, respectively. ${ }^{8,9}$ Because ceria is recycled, the net reactions are $\mathrm{H}_{2} \mathrm{O} \rightarrow \mathrm{H}_{2}+1 / 2 \mathrm{O}_{2}$ and/or $\mathrm{CO}_{2} \rightarrow \mathrm{CO}+1 / 2 \mathrm{O}_{2}$, with gaseous fuel and $\mathrm{O}_{2}$ evolving in different steps. Recently, the isothermal redox cycle has been thermodynamically examined ${ }^{10}$ and experimentally demonstrated with hercynite ${ }^{11}$ and ceria. ${ }^{12}$

The solar-to-fuel energy conversion efficiency of such a $\mathrm{H}_{2} \mathrm{O}$ / $\mathrm{CO}_{2}$-splitting thermochemical cycle, defined as the ratio of the heating value of the fuel produced to the solar energy input, depends highly on the thermodynamics ( $\delta$ under given $p$ and $T$, for example), the reaction kinetics, and the transfer of concentrated solar energy to the reaction site. The first reduction step 
is usually performed with solar reactors containing porous structures of the redox material that are directly exposed to the high-flux solar irradiation. ${ }^{13-18}$ Thus, low optical thickness is desired to enable volumetric radiative absorption and uniform heating of the porous structure. On the other hand, the second oxidation step with $\mathrm{H}_{2} \mathrm{O}$ or $\mathrm{CO}_{2}$ has been shown to be largely surface dependent, and as such large specific surface area (SSA) is desired to enhance reaction kinetics. ${ }^{19,20}$ However, the porous structure supporting the redox material generally features only one of the two desired properties: either high $\mathrm{SSA}^{18-21}$ or low optical thicknesses, ${ }^{13,22-26}$ as the former comes at the expense of high radiative opacity while the latter comes at the expense of lower SSA.

Porous structures with void sizes in the $\mu \mathrm{m}$-range, e.g. felts, ${ }^{21}$ exhibit high SSA that are favorable for the oxidation step. They also exhibit high opacity for incident thermal radiation and therefore absorb it mainly on their exposed surface, resulting in steep temperature gradients across the structure thickness because of the inherently poor thermal conductivity. Thus, the regions directly below the exposed surface reach temperatures sufficiently high for the reduction step to proceed at reasonable rates, whereas the deeper regions reach lower temperatures where reaction rates are diminishingly low. In contrast, porous structures with void sizes in the mm-range, e.g. reticulated foams ${ }^{22-26}$ or honeycombs, ${ }^{13}$ can absorb incident thermal radiation more homogeneously. Because of their relatively low optical thicknesses, radiation can penetrate and be absorbed volumetrically, which in turn leads to more uniform temperature profiles across the structure thickness. However, because of their low SSA, the reaction rates of the oxidation step are slower compared to those obtained with the aforementioned $\mu \mathrm{m}$-range porous materials. ${ }^{22}$

In light of the apparent tradeoffs between rapid reaction kinetics and efficient radiation heat transfer, we have engineered ceria reticulated porous ceramic (RPC) structures which are capable of combining both of the desired properties, namely; low optical thickness for volumetric radiative absorption during reduction, and high SSA for rapid reaction rates during oxidation. In the present study we report on the synthesis, characterization, and experimental assessment of such ceria RPC structures. Void sizes on two scales - dual-scale porosity - have been incorporated within the structure: one in the mm-range to achieve relatively low optical thickness for volumetric absorption of concentrated solar radiation, and a second smaller void size within the struts in the $\mu \mathrm{m}$-range to increase SSA for fast oxidation rates with $\mathrm{H}_{2} \mathrm{O}$ and $\mathrm{CO}_{2}$. As it will be shown in the analysis that follows, these dual-scale porosity RPC structures are morphologically stable when cycling at reduction temperatures of $1773 \mathrm{~K}$ and are capable of increasing oxidation rates by roughly 10 times compared to analogous RPC structures without the implementation of $\mu \mathrm{m}$-size porosity in the struts.

\section{Results and discussion}

\section{Characterization of structures}

Fig. 1 shows a photograph of a representative RPC ceria sample produced with 50 vol\% pore-forming agent (RPC-50), alongside a SEM micrograph (inset) of one of its struts. The RPC structure

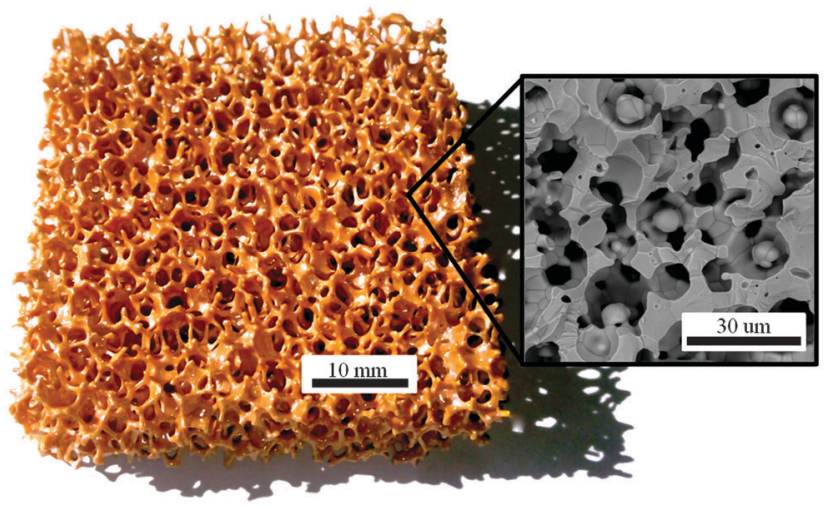

Fig. 1 Photograph of an RPC ceria sample with dual-scale porosity produced with 50 vol\% of pore-forming agent. Inset: SEM micrograph of a break plane of its struts.

is composed of a network of large voids with a mean diameter $d_{\text {mean }}=2.5 \mathrm{~mm}$ that are bounded by struts and, within the struts, a sub-network of small voids with $d_{\text {mean }}=10 \mu \mathrm{m}$. Visually, there is no observable difference between this RPC and those produced without pore forming agents, i.e. without $\mu \mathrm{m}$-range porosity in the struts. Samples ranging from 0 to 50 vol\% pore-forming agents have been produced and are denoted by RPC-0..50. Their porosity and surface area are listed in Table 1. Evidently, increasing the amount of poreforming agent into the struts leads to a more porous structure and higher SSA. The total sample porosity, $\varepsilon_{\text {sample }}$, defined as the fraction of all void spaces divided by the overall volume of the sample, remained relatively constant in the range 0.8-0.82. In contrast, the effective strut porosity, $\varepsilon_{\text {strut }}$, defined as the volume of the open $\mu \mathrm{m}$-voids of a control volume inside a strut divided by the control volume, increased significantly from 0.03 to 0.44 when the amount of pore-forming agent introduced increased from 10 to $50 \mathrm{vol} \%$. As it will be verified by SEM, RPC-10, and RPC-20 are comprised of closed pores in the struts, while higher amounts of pore-forming agent result in an interconnected pore network. Thus, those with 30 vol\% pore-forming agent and greater have considerably higher $\varepsilon_{\text {strut }}$ and SSA. For example, for RPC-30 $\varepsilon_{\text {strut }}=0.18$ and SSA $=0.066 \mathrm{~m}^{2} \mathrm{~g}^{-1}$, values which are roughly four times larger than those corresponding to RPC-20. The marginal increase in $\varepsilon_{\text {sample }}$ with an increasing amount of pore-forming agent is due to the larger strut thickness

Table 1 Porosity and surface area of the ceria RPC samples fabricated with different amounts of pore-forming agent

\begin{tabular}{lllll}
\hline Name & $\begin{array}{l}\text { Pore-forming } \\
\text { agent (vol\%) }\end{array}$ & $\varepsilon_{\text {sample }}{ }^{a}$ & $\varepsilon_{\text {strut }}{ }^{b}$ & $\begin{array}{l}\mathrm{SSA}^{b} \\
\left(\mathrm{~m}^{2} \mathrm{~g}^{-1}\right)\end{array}$ \\
\hline RPC-0 & 0 & $0.80 \pm 0.03$ & $\begin{array}{l}\text { Below detectable } \\
\text { range }\end{array}$ & $0.000145^{c}$ \\
RPC-10 & 10 & $0.79 \pm 0.03$ & 0.03 & 0.0097 \\
RPC-20 & 20 & $0.80 \pm 0.03$ & 0.05 & 0.019 \\
RPC-30 & 30 & $0.76 \pm 0.03$ & 0.18 & 0.066 \\
RPC-50 & 50 & $0.82 \pm 0.03$ & 0.44 & 0.095
\end{tabular}

${ }^{a}$ Determined by measurement of sample mass and volume. ${ }^{b}$ Determined by mercury porosimetry. ${ }^{c}$ Determined based on tomographic scans. ${ }^{22}$ 

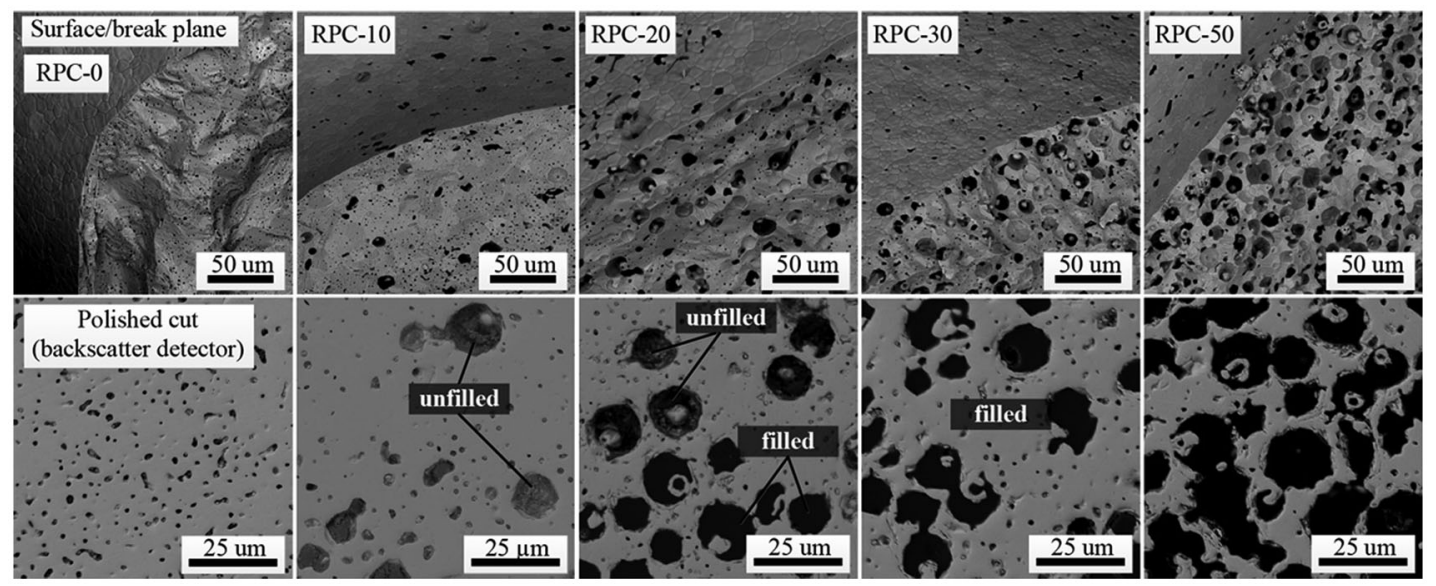

Fig. 2 Top: SEM micrographs of the surface and break plane of RPC samples produced with varying amounts of pore-forming agent in the range 0 to 50 vol\%. Bottom: SEM micrographs taken using a back-scattered electron detector of polished cuts through a single strut of the different samples. Samples were filled with an organic resin prior to cutting for examining pore interconnectivity. Table 1 lists the morphological characteristics of the RPC samples.

as a result of the slurry viscosity increasing with a higher amount of carbon particles added. For all samples, $\varepsilon_{\text {strut }}$ was lower than the pre-fired volume fraction of carbon particles added because of closed pores and shrinkage of the RPC structure during the sintering process.

Microscopically, the effect of the amount of pore-forming agent on the porous network can be seen in Fig. 2. Here we show SEM images of surface/break-planes (top) and polished cross sections (bottom) of the struts for the RPC samples listed in Table 1. For all cases, the strut surface appears less porous than the bulk, but there are no obvious gradients or regions of varying porosity throughout the bulk. Before cross sectional cutting, samples were immersed into organic resin that penetrated through all available open (connecting) pores. The contrast in color between filled and unfilled pores indicates the open and closed pores, respectively. For RPC-0, RPC-10, and RPC-20, most of the pores are closed. For RPC-30 and RPC-50, almost all pores are open, i.e. interconnected. These observations are consistent with the measurements listed in Table 1. In addition to pores resulting from pore-forming agents, all samples contained small intrinsic pores with a diameter of around $2 \mu \mathrm{m}$ due to incomplete sintering or gas encapsulations during the sintering process.

\section{Thermogravimetric analysis}

Samples were subjected to thermochemical redox cycling in a thermogravimetric analyzer. Samples were reduced at $1773 \mathrm{~K}$ under an Ar atmosphere with a background $p_{\mathrm{O}_{2}}$ of $1.8 \times 10^{-4} \mathrm{~atm}$, measured by gas chromatography. Fig. 3 shows the relative weight change and temperature as a function of time during a single $\mathrm{CO}_{2}$-splitting redox cycle with RPC-0 (dashed line) and RPC-50 (solid line). The reduction step (eqn (1)) was performed at $1773 \mathrm{~K}$ and $p_{\mathrm{O}_{2}}<1.8 \times 10^{-4}$ atm in $\operatorname{Ar}(\mathrm{g})$; the oxidation step (eqn (2b)) was performed at $1273 \mathrm{~K}$ and $p_{\mathrm{CO}_{2}}=0.385 \mathrm{~atm}$. Total gas flow rates during reduction and oxidation were $260 \mathrm{~mL} \mathrm{~min}^{-1}$. It is found that $\varepsilon_{\text {strut }}$ did not have an observable influence on the reduction extents. Both samples began to noticeably reduce at around

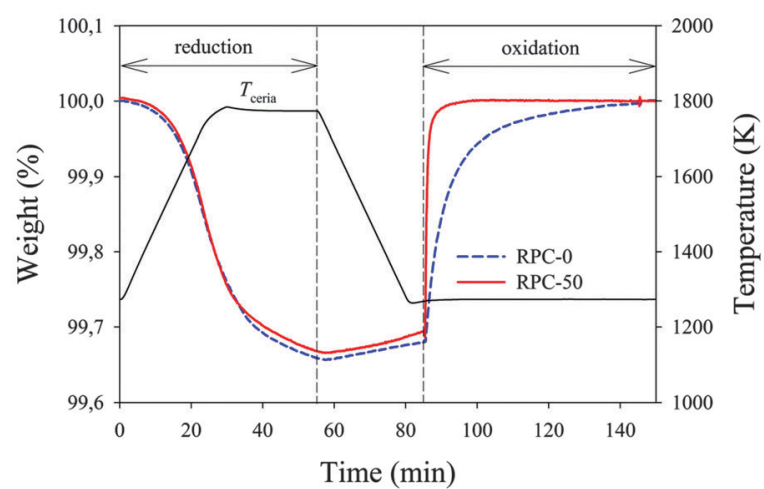

Fig. 3 Variation of the relative weight and temperature as a function of time during a $\mathrm{CO}_{2}$-splitting redox cycle for RPC-O (dashed line) and RPC50 (solid line) as measured by TGA. The first reduction step was performed at $1773 \mathrm{~K}$ and $p_{\mathrm{O}_{2}}<1.8 \times 10^{-4}$ atm in $\operatorname{Ar}(\mathrm{g})$; the second oxidation step was performed at $1273 \mathrm{~K}$ and $p_{\mathrm{CO}_{2}}=0.385 \mathrm{~atm}$.

$1273 \mathrm{~K}$ and reached roughly the same reduction extents. The nonstoichiometry $\delta$ was 0.037 and 0.038 for RPC-50 and RPC-0, respectively, in agreement with the thermodynamic equilibrium values predicted from Panlener et al. ${ }^{27}$ The small difference in $\delta$ is attributed to measurement accuracy.

After reduction, samples were cooled to $1273 \mathrm{~K}$. The increase in weight during the cooling period ( 55 to $85 \mathrm{~min}$ in the $x$-axis) was due to partial re-oxidation with residual $\mathrm{O}_{2}$ in the system. The oxidation step was initiated at $1273 \mathrm{~K}$ by supplying $\mathrm{CO}_{2}$. Shortly afterwards, a rapid increase in weight for both samples, accompanied by CO evolution, indicated the onset of oxidation. The oxidation of RPC-50 was noticeably more rapid than that of RPC-0: $90 \%$ of the initial oxidation state was reached after 3 min for RPC-50 as compared to $28 \mathrm{~min}$ for RPC-0. Additionally, the average CO production rate to attain $90 \%$ of the initial oxidation state was roughly one order of magnitude higher: $2.22 \pm 0.19 \mathrm{~mL} \min ^{-1} \mathrm{~g}^{-1} \mathrm{CeO}_{2}$ for RPC-50 versus $0.22 \pm$ $0.06 \mathrm{~mL} \mathrm{~min}^{-1} \mathrm{~g}^{-1} \mathrm{CeO}_{2}$ for RPC-0. These remarkable differences are attributed to the difference in available SSA of the two 


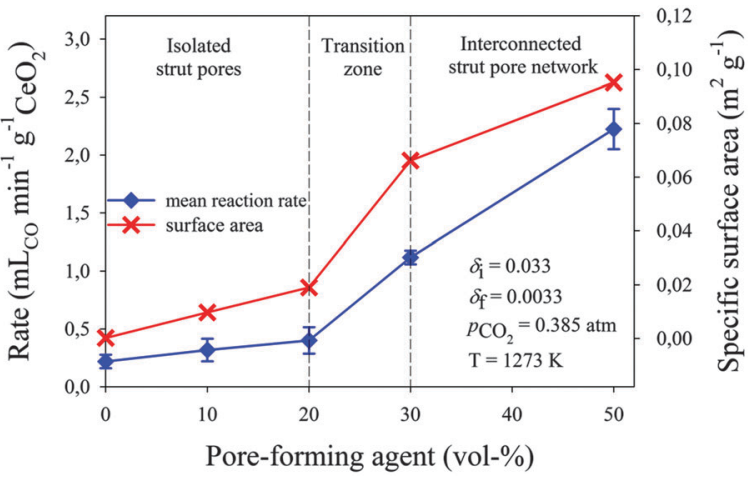

Fig. 4 Mean CO evolution rate during the oxidation step and SSA as a function of pore-forming agent vol\% for all RPC samples following thermal reduction at $1773 \mathrm{~K}$. Error bars indicate the standard deviation from the experimentally measured average values.

samples (see Table 1), as confirmed by mercury porosimetry measurements. ${ }^{7,19,20,22}$

Fig. 4 shows the mean CO evolution rate during the oxidation step (to attain $90 \%$ of the initial oxidation state) and the SSA as a function of pore-forming agent vol\% for all RPC samples following thermal reduction at $1773 \mathrm{~K}$. Error bars indicate the standard deviation from the experimentally measured average values. For all cases, the rate scales well with measured SSA. For samples with closed pores RPC-0, RPC-10 and RPC-20, the CO production rate increased only marginally with a poreforming agent, from $0.22 \pm 0.06 \mathrm{~mL} \mathrm{~min}{ }^{-1} \mathrm{~g}^{-1} \mathrm{CeO}_{2}$ to $0.40 \pm$ $0.13 \mathrm{~mL} \mathrm{~min}^{-1} \mathrm{~g}^{-1} \mathrm{CeO}_{2}$. For samples with open (interconnected) pores RPC-30 and RPC-50, the rates increased substantially to $1.12 \pm 0.06 \mathrm{~mL} \mathrm{~min}{ }^{-1} \mathrm{~g}^{-1} \mathrm{CeO}_{2}$ and $2.22 \pm 0.19 \mathrm{~mL} \mathrm{~min}^{-1} \mathrm{~g}^{-1}$ $\mathrm{CeO}_{2}$, respectively. These rates are comparable to those obtained with porous monolithic ceria of SSA of $0.1 \mathrm{~m}^{2} \mathrm{~g}^{-1}$ under similar conditions. ${ }^{18}$ The beneficial effect of an interconnected pore network on the fuel production kinetics was also reported by Venstrom et $a l^{19}$ for ceria structures in a fixed bed reactor. Based on their results with highly porous, 3D-ordered ceria structures with SSA > $10 \mathrm{~m}^{2} \mathrm{~g}^{-1}$, it is expected that further increasing the SSA of the RPC would result in even higher rates than presently reported. On the other hand, increasing SSA implies reducing the specific mass $\left[\mathrm{kg} \mathrm{m} \mathrm{m}^{-3}\right]$. For solar reactors containing a fixed volume of ceria (without continuous feeding or removal of ceria), ${ }^{13,18,21,22,28-30}$ increasing SSA effectively lowers the total mass of reactive material and, consequently, lowers the fuel output per cycle. Thus, optimization of porosity is only one of the several factors to consider when maximizing the solar-to-fuel conversion efficiency.

Fig. 5 shows the mean $\mathrm{CO}$ evolution rates and CO production yields per cycle as a function of the cycle number for 20 consecutive redox cycles with RPC-50. The reduction step was performed at $1773 \mathrm{~K}$ and $p_{\mathrm{O}_{2}}<1.8 \times 10^{-4}$ atm for $30 \mathrm{~min}$; the oxidation step was performed at $1273 \mathrm{~K}$ and $p_{\mathrm{CO}_{2}}=0.385 \mathrm{~atm}$ for $60 \mathrm{~min}$. The total gas flow rate during reduction and oxidation steps was $260 \mathrm{~mL} \mathrm{~min}^{-1}$. The CO production yield per cycle, calculated from the initial nonstoichiometry $\delta_{\mathrm{i}}=$ 0.033 to the final nonstoichiometry $\delta_{\mathrm{f}}=0.0033$, was roughly constant for all 20 cycles at $4.47 \pm 0.06 \mathrm{~mL} \mathrm{~g}^{-1} \mathrm{CeO}_{2}$ per cycle.

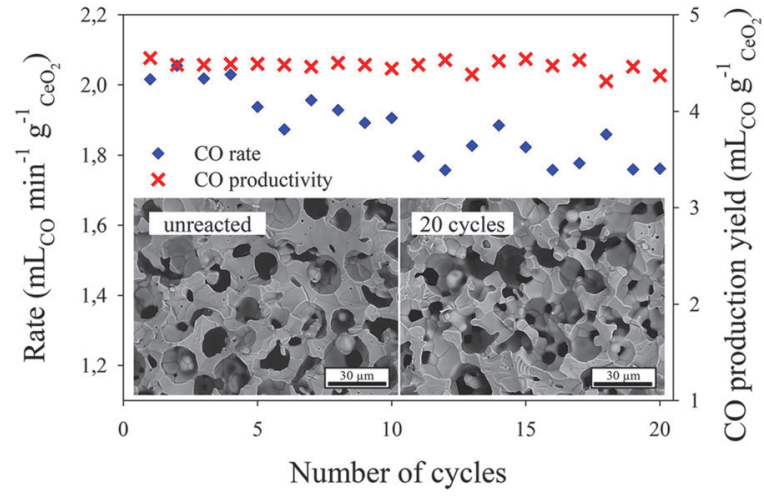

Fig. 5 Mean $\mathrm{CO}$ evolution rates and $\mathrm{CO}$ production yields per cycle as a function of the cycle number for 20 consecutive redox cycles with RPC-50, and SEM micrographs before (left) and after (right) the 20 cycles. The reduction step was performed at $1773 \mathrm{~K}$ and $p_{\mathrm{O}_{2}}<1.8 \times 10^{-4} \mathrm{~atm}$ for $30 \mathrm{~min}$; the oxidation step was performed at $1273 \mathrm{~K}$ and $p_{\mathrm{CO}_{2}}=0.385 \mathrm{~atm}$ for $60 \mathrm{~min}$

This indicates stable performance over time. However, a slight and linear decrease in the oxidation rates (to attain $90 \%$ reaction extent)

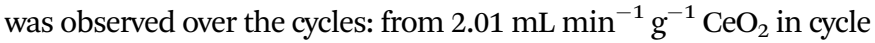
\#1 to $1.76 \mathrm{~mL} \mathrm{~min}^{-1} \mathrm{~g}^{-1} \mathrm{CeO}_{2}$ in cycle \#20, which corresponds to an average increase in oxidation time of 0.9 seconds per cycle. Also shown in Fig. 5 are the SEM micrographs before (left) and after (right) the 20 cycles. No obvious changes in morphology were observed, but SSA decreased slightly from initially $0.098 \mathrm{~m}^{2} \mathrm{~g}^{-1}$ $\mathrm{CeO}_{2}$ to $0.089 \mathrm{~m}^{2} \mathrm{~g}^{-1} \mathrm{CeO}_{2}$.

To further assess the morphological stability, RPC-50 samples were placed in a furnace under atmospheric air for $120 \mathrm{~h}$ at $1773 \mathrm{~K}$ and $1873 \mathrm{~K}$. Fig. 6 shows the SEM micrographs of the strut's cross section for: (a) the unreacted sample; (b) after $120 \mathrm{~h}$ at $1773 \mathrm{~K}$; and (c) after $120 \mathrm{~h}$ at $1873 \mathrm{~K}$. The integrity of the strut was maintained. Although there was some grain growth, the interconnected network was not affected. However, SSA decreased from initially $0.095 \mathrm{~m}^{2} \mathrm{~g}^{-1} \mathrm{CeO}_{2}$ to $0.056 \mathrm{~m}^{2} \mathrm{~g}^{-1}$ $\mathrm{CeO}_{2}(120 \mathrm{~h}$ at $1773 \mathrm{~K})$ and $0.036 \mathrm{~m}^{2} \mathrm{~g}^{-1} \mathrm{CeO}_{2}(120 \mathrm{~h} 1873 \mathrm{~K})$. More extensive long-term cycling tests are required to evaluate the effect of such grain growth. Chueh et al. ${ }^{7}$ reported a strong decrease in reaction rates over the first 100 cycles when using porous monolithic ceria as a result of sintering, but constant rates were achieved during the following 400 cycles. In general, structures with nm-range pores are more likely to sinter, thereby losing a substantial amount of SSA over the initial cycles. ${ }^{19-21}$ We attribute the better morphological stability observed here to the larger pores $\left(d_{\text {mean }}=10 \mu \mathrm{m}\right.$ in the struts) and to pre-sintering at temperatures higher than the maximum temperature during cycling (1873 versus $1773 \mathrm{~K}$ ).

It is generally accepted that oxidation of ceria with $\mathrm{CO}_{2}$ is a surface-limited process. ${ }^{19,31}$ Observations in this study confirmed that the oxidation rate is strongly linked to the SSA (see Fig. 4). Further confirmation that the rates for RPCs with and without dual-scale porosity were limited by the same rate controlling mechanism was accomplished by performing isothermal thermogravimetric studies with RPC-0 (without porosity in the struts) and RPC-50 (with dual porosity). Fig. 7(a and b) shows the 
(a)
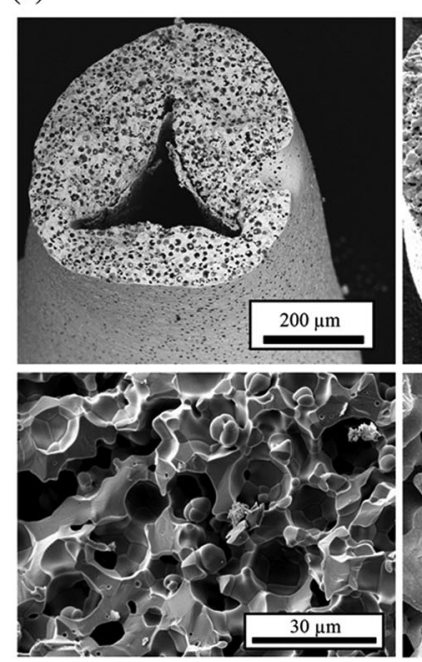

(b)

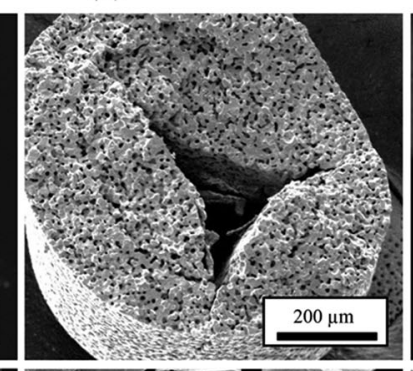

(c)

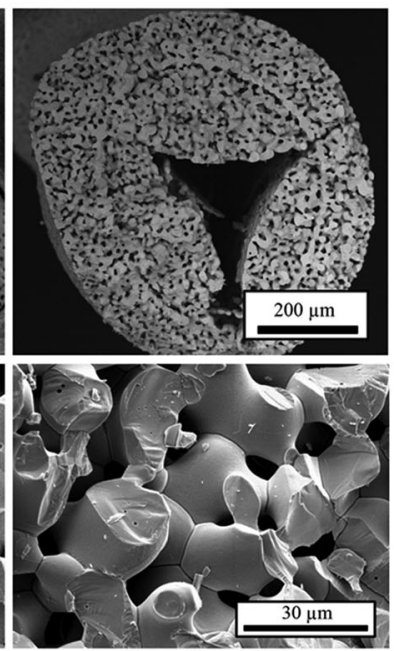

Fig. 6 SEM micrographs of a strut's cross section of RPC-50: (a) unreacted; (b) after $120 \mathrm{~h}$ at $1773 \mathrm{~K}$; and (c) after $120 \mathrm{~h}$ at $1873 \mathrm{~K}$

relative mass change as a function of time during the oxidation step at temperatures ranging from $873-1273 \mathrm{~K}$ and $p_{\mathrm{CO}_{2}}=0.5 \mathrm{~atm}$ for RPC-50 (a) and RPC-0 (b). Insets indicate the relative mass change $v s$. time at elevated temperatures $(>1073 \mathrm{~K})$ where the oxidation rate is inversely related to temperature. The oxidation rates increased with temperature between 873 and $1073 \mathrm{~K}$, but the opposite is true for higher temperatures due to the reverse reaction (eqn (2b)) becoming thermodynamically favorable. Additionally, the influence of thermal reduction cannot be discounted and may also influence the observed rates.

Arrhenius plots derived from such data are shown in Fig. 7 (c) for RPC-50 at $p_{\mathrm{CO}_{2}}=0.075$ and $0.5 \mathrm{~atm}$, and for RPC- 0 at $p_{\mathrm{CO}_{2}}=0.5 \mathrm{~atm}$. Here, the reaction rate at $\delta=0.015$ is shown as a function of the inverse temperature. The rates between RPC-0 and RPC-50 differ by 2 to 3 orders of magnitude. Qualitatively, both samples display the same trend with increasing temperature, namely an Arrhenius-type temperature dependence at low temperatures in which the forward reaction (eqn (2b)) is thermodynamically favored, and a region at higher temperatures deviating from a typical Arrhenius-type temperature dependence due to the influence of the reverse reaction (eqn (2b)) and/of thermal reduction. Apparent activation energies $\left(E_{\mathrm{a}}\right)$ were determined from the slope of the linear fits over the range of temperatures indicated in the figure. Corresponding values were: $E_{\mathrm{a}}=135.7 \mathrm{~kJ} \mathrm{~mol}{ }^{-1}$ for RPC-50 at $p_{\mathrm{CO}_{2}}=0.5 \mathrm{~atm}$, $E_{\mathrm{a}}=90.3 \mathrm{~kJ} \mathrm{~mol}{ }^{-1}$ for RPC-50 at $p_{\mathrm{CO}_{2}}=0.075$ atm; and $E_{\mathrm{a}}=101.2 \mathrm{~kJ} \mathrm{~mol}^{-1}$ for RPC-0 at $p_{\mathrm{CO}_{2}}=0.5 \mathrm{~atm}$. The higher $E_{\mathrm{a}}$ for RPC-50 is attributed to the reaction exothermicity, resulting in temperature measurements deviating from the actual sample temperature. Assuming no heat is dissipated during oxidation, the maximum temperature increase can reach:

$$
\Delta T_{\text {sample }}=\frac{\Delta h_{\mathrm{rxn}} \delta_{\mathrm{i}}}{C_{p, \mathrm{CeO}_{2}}} \approx 100 \mathrm{~K}
$$

where the reaction enthalpy $\left(\Delta h_{\mathrm{rxn}}\right)$ was calculated from the oxygen molar enthalpy for ceria oxidation $\left(\mathrm{CeO}_{2-\delta}+\delta / 2 \mathrm{O}_{2}(\mathrm{~g}) \leftrightarrow \mathrm{CeO}_{2}\right)^{27}$ and the enthalpy of $\mathrm{CO}_{2}$ reduction $\left(\mathrm{CO}_{2}(\mathrm{~g}) \leftrightarrow \mathrm{CO}(\mathrm{g})+1 /\right.$ $\left.2 \mathrm{O}_{2}(\mathrm{~g})\right),{ }^{32}$ and the ceria heat capacity $\left(C_{p, \mathrm{CeO}_{2}}\right)$ was determined from Riess et al. ${ }^{33} \Delta T_{\text {sample }}$ is strongly tied to the reaction rate because of the time available to dissipate the generated heat. Thus, $\Delta T_{\text {sample }}$ should become smaller for slower reaction rates, and the corresponding $E_{\mathrm{a}}$ should decrease. We tested this hypothesis by decreasing $p_{\mathrm{CO}_{2}}$ from 0.5 to $0.075 \mathrm{~atm}$. As expected, the rates became slower and, consequently, $E_{\mathrm{a}}$ of RPC-50 decreased considerably at lower $p_{\mathrm{CO}_{2}}$, reaching a value approaching that of RPC-0. Different rate controlling mechanisms between RPC-50 and RPC-0, such as solid state diffusion or pore diffusion, could not explain such behavior. For example, both samples were oxidized using $\mathrm{O}_{2}$ and $\mathrm{CO}_{2}$ as oxidants under same conditions, and the resultant rates were considerably faster with $\mathrm{O}_{2}$ than those with $\mathrm{CO}_{2}$. Additionally, limitations related to $\mathrm{CO}_{2}$ pore diffusion through RPC-50 would result in a lower $E_{\mathrm{a}}$ than that measured for RPC- $0 .{ }^{34}$

\section{High-flux radiation experimentation}

For the purpose of corroborating the superior performance of the dual-scale RPC under realistic solar operating conditions, tests were carried out using a solar cavity-receiver directly exposed to $3.8 \mathrm{~kW}$ of radiation power at a mean solar flux concentration of 3015 suns over the aperture. Results of a single redox cycle using RPC-30 are shown in Fig. 8. During the solar reduction step, the temperature rose rapidly at a peak heating rate of $184 \mathrm{~K} \mathrm{~min}^{-1}$ and reached a maximum temperature of $1847 \mathrm{~K}$. Above $1200 \mathrm{~K} \mathrm{O}_{2}$ evolution began and reached peak and average rates of $0.27 \pm 0.05 \mathrm{~mL} \mathrm{~min}^{-1} \mathrm{~g}^{-1} \mathrm{CeO}_{2}$ and $0.17 \pm 0.05 \mathrm{~mL} \mathrm{~min}{ }^{-1} \mathrm{~g}^{-1} \mathrm{CeO}_{2}$, respectively. The total $\mathrm{O}_{2}$ evolution was $2.52 \pm 0.09 \mathrm{~mL} \mathrm{~g}^{-1} \mathrm{CeO}_{2}$ corresponding to $\delta=$ 0.039. After $15 \mathrm{~min}$, the radiative power input was stopped, resulting in the immediate interruption of the reduction reaction and a decrease in reactor temperature. During the non-solar oxidation step, shortly after injection of $\mathrm{CO}_{2}$, rapid production of $\mathrm{CO}$ at peak and average rates of $1.13 \pm 0.11 \mathrm{~mL} \mathrm{~min}^{-1} \mathrm{~g}^{-1} \mathrm{CeO}_{2}$ and $0.63 \pm 0.04 \mathrm{~mL} \mathrm{~min}^{-1} \mathrm{~g}^{-1} \mathrm{CeO}_{2}$ was observed. Total $\mathrm{CO}$ 


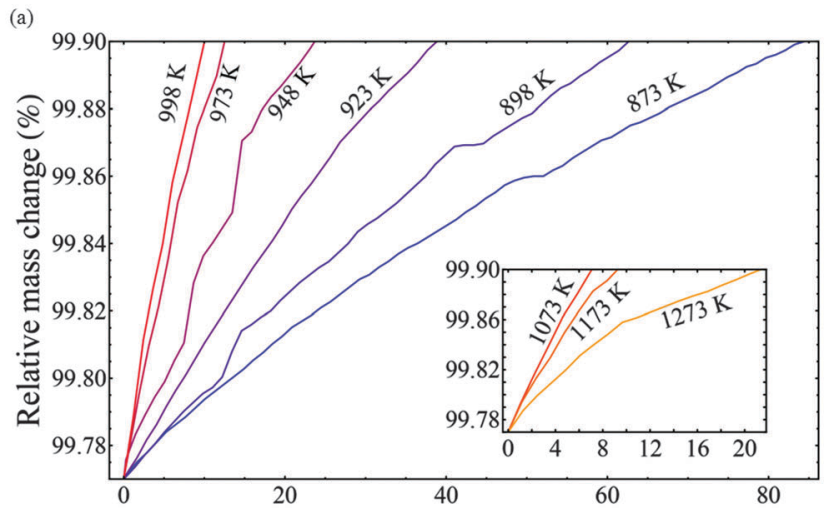

(b)

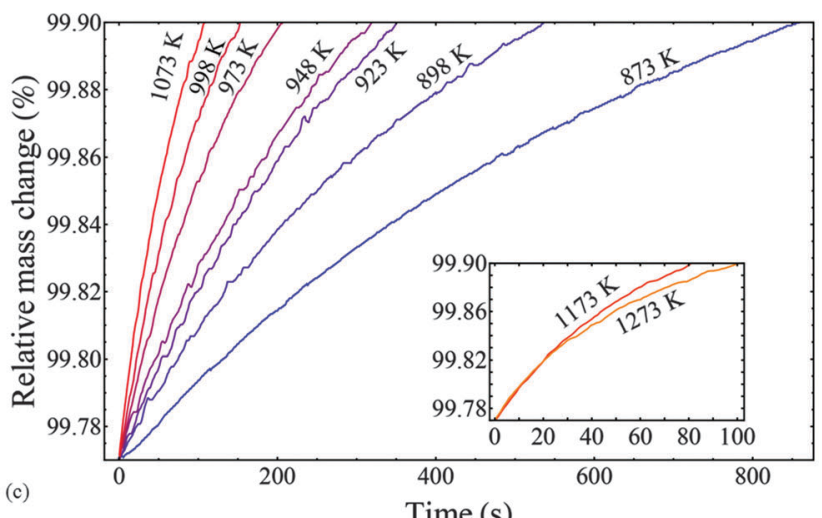

(c)

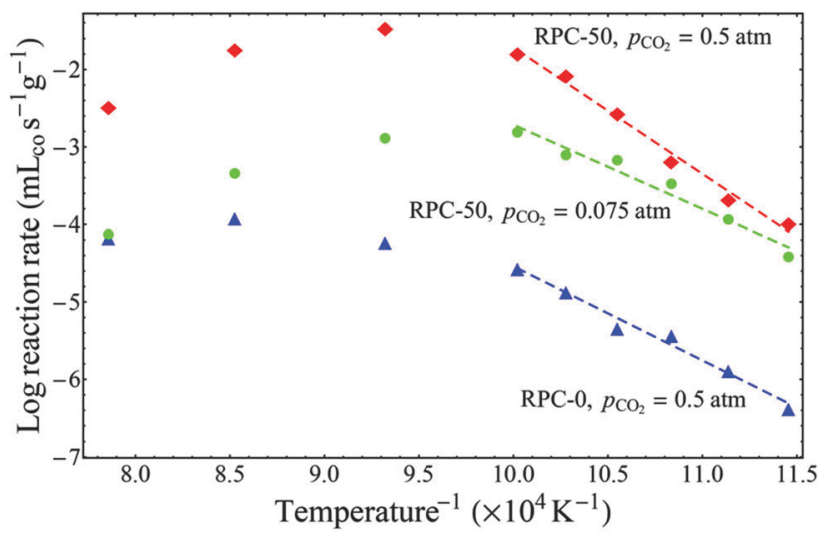

Fig. 7 Top (a, b): relative mass change as a function of time during the oxidation step at temperatures in the range $873-1273 \mathrm{~K}$ and $p_{\mathrm{CO}_{2}}=0.5 \mathrm{~atm}$ for RPC-50 (a) and RPC-O (b). Insets indicate the relative mass change vs. time at elevated temperatures ( $>1073 \mathrm{~K}$ ) where the oxidation rate is inversely related to temperature. Bottom (c): Arrhenius plots for the oxidation rate $(\delta=0.015)$ of $\mathrm{RPC}-50$ at $p_{\mathrm{CO}_{2}}=0.075$ and $0.5 \mathrm{~atm}$, and of RPC-0 at $p_{\mathrm{CO}_{2}}=0.5 \mathrm{~atm}$. Lines correspond to linear fits over the range of temperatures indicated. Corresponding apparent activation energies are $E_{\mathrm{a}}=135.7 \mathrm{~kJ} \mathrm{~mol} \mathrm{~m}^{-1}$ for RPC-50 at $p_{\mathrm{CO}_{2}}=0.5 \mathrm{~atm}, E_{\mathrm{a}}=90.3 \mathrm{~kJ} \mathrm{~mol}{ }^{-1}$ for RPC -50 at $p_{\mathrm{CO}_{2}}=$ $0.075 \mathrm{~atm}$; and $E_{\mathrm{a}}=101.2 \mathrm{~kJ} \mathrm{~mol}{ }^{-1}$ for RPC-0 at $p_{\mathrm{CO}_{2}}=0.5 \mathrm{~atm}$.

production was $5.02 \pm 0.33 \mathrm{~mL} \mathrm{~g}^{-1} \mathrm{CeO}_{2}$ resulting in a fuel to oxygen ratio of $1.99 \pm 0.21$ implying that $\delta$ was fully exploited for fuel production.

As expected, the behavior of RPC-30 during the reduction step is similar to the previously tested RPC- $0 .{ }^{22}$ We attribute this to heat transfer limitations rather than chemical kinetics ${ }^{22}$

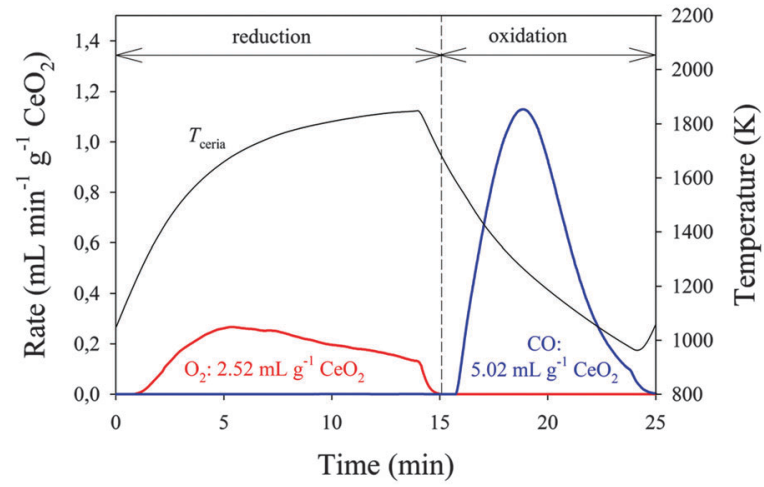

Fig. 8 Temperature of the dual-scale RPC, $\mathrm{O}_{2}$ and $\mathrm{CO}$ evolution rate during a redox cycle performed in a solar cavity-receiver exposed to highflux thermal radiation. Experimental conditions: $3.8 \mathrm{~kW}$ radiative power input and $6 \mathrm{~L} \mathrm{~min}{ }^{-1} \mathrm{Ar}$ during the reduction step; no radiative power input and $6 \mathrm{~L} \min ^{-1} \mathrm{CO}_{2}$ during the oxidation step.

and therefore the strut porosity did not affect these rates. In contrast, the peak oxidation rate of RPC-30 was more than twice that of RPC- $0,{ }^{22}$ and complete oxidation was achieved within 10 min instead of around 30 min with RPC-0. While the oxidation time is 3 times faster and not 5 times faster as obtained with the TGA (see Fig. 4), a direct comparison between TGA and solar runs is difficult because temperatures and gas compositions within the solar reactor vary greatly in both space and time. Thus, anything beyond a qualitative agreement is not expected.

The solar-to-fuel energy conversion efficiency ( $\left.\eta_{\text {solar-to-fuel }}\right)$ is defined as the ratio of the heating value of the CO produced to the solar energy input. Any additional energy input should be accounted for; in our case we account for the energy penalty associated with the use of inert gas to promote the reduction step. $\eta_{\text {solar-to-fuel }}$ is calculated by integration of the CO production and energy consumption over the complete redox cycle as:

$$
\eta_{\text {solar-to-fuel }}=\frac{\Delta H_{\mathrm{CO}} \int r_{\mathrm{CO}} \mathrm{d} t}{\int P_{\text {solar }} \mathrm{d} t+E_{\text {inert }} \int r_{\text {inert }} \mathrm{d} t}
$$

where $r_{\mathrm{CO}}$ is the molar rate of $\mathrm{CO}$ production during oxidation, $\Delta H_{\mathrm{CO}}$ is the heating value of $\mathrm{CO}, P_{\text {solar }}$ is the solar radiative power input, $r_{\text {inert }}$ is the flow rate of the inert gas during reduction, and $E_{\text {inert }}$ is the energy required to separate the inert gas (assumed $20 \mathrm{~kJ} \mathrm{~mol}^{-1}$ ). ${ }^{35}$ Based on the experimental data presented in Fig. 8, $\eta_{\text {solar-to-fuel }}=1.72 \pm 0.1 \%$. This value is similar to $\eta_{\text {solar-to-fuel }}$ obtained with RPC-0 under comparable solar experimental conditions $^{22}(1.73 \%)$ but with $33 \%$ less $\mathrm{CeO}_{2}$ inside the reactor (RPC-0: $1413 \mathrm{~g} \mathrm{CeO}_{2}$, RPC-30: $948 \mathrm{~g} \mathrm{CeO}_{2}$ ). Therefore, $\eta_{\text {solar-to-fuel }}$ can be enhanced by increasing the mass loading of the dual-scale RPC and through optimization of pore-sizes on both scales.

\section{Summary and conclusions}

We have fabricated novel RPC structures made of ceria containing dual-scale porosity for application in solar thermochemical redox cycles for splitting $\mathrm{H}_{2} \mathrm{O}$ and $\mathrm{CO}_{2}$. The mm-size porosity enables volumetric absorption of concentrated solar radiation and 
uniform heating during reduction, while the $\mu \mathrm{m}$-size porosity within the struts increases the SSA for enhanced reaction kinetics during oxidation. The dual-scale porosity caused a remarkable increase in the $\mathrm{CO}$ evolution rate by an order of magnitude, from $0.22 \pm$ $0.06 \mathrm{~mL} \mathrm{~min}^{-1} \mathrm{~g}^{-1} \mathrm{CeO}_{2}$ (RPC-0) to $2.22 \pm 0.19 \mathrm{~mL} \mathrm{~min}^{-1} \mathrm{~g}^{-1}$ $\mathrm{CeO}_{2}$ (RPC-50), and consequently a significant decrease in the duration of the oxidation step from $28 \mathrm{~min}$ to $3 \mathrm{~min}$. Oxidation rates scaled with SSA, which strongly increased when interconnection of the strut pores was achieved. Measurements of the apparent activation energy for RPC with dual-scale porosity (RPC-50) and without (RPC-0) further confirmed the surfacecontrolling mechanism. The strut porosity did not have a measurable effect on the observed $\mathrm{O}_{2}$ evolution during the reduction step. Stable CO production yields were obtained for 20 consecutive redox cycles, but a slight decrease in the oxidation rates was observed over time. SEM images before and after the 20 cycles did not show any obvious morphological changes, but a slight decrease in SSA was measured. SEMs taken after $120 \mathrm{~h}$ at 1773 and $1873 \mathrm{~K}$ revealed moderate grain growth. Nevertheless, the integrity of the struts and the interconnectivity of the strut network were preserved.

Testing of the dual-scale RPC-30 in a solar cavity-receiver exposed to concentrated thermal radiation corroborated the TGA results. The duration of the oxidation step was decreased to one third compared to solar tests with RPC-0, thus increasing overall fuel production yield per unit time. Further improvement in overall solar-to-fuel conversion efficiency is expected through optimization of the hierarchical pore structure with the aid of direct pore-level numerical simulations. ${ }^{36,37}$

\section{Experimental setup and methods}

\section{Synthesis of ceria RPC}

Samples were manufactured by the replication method. ${ }^{38}$ Cerium(Iv)-oxide powder (particle size $<5 \mu \mathrm{m}, 99.9 \%$ purity, Sigma Aldrich) and spherical carbon pore-forming agent particles (particle size 0.4-12 $\mu \mathrm{m}$, HTW Hochtemperatur-Werkstoffe GmbH) were mixed with water in a 5:1 mass ratio, based on a previously published recipe. ${ }^{39}$ Organic deflocculating agent Dolapix CE 64 (Zimmer \& Schwartz) was added in a ratio of $0.83 \mathrm{wt} \%$ of solid load. Mixing and deagglomeration were achieved by ball milling with $\mathrm{ZrO}_{2}$ grinding media for 24 hours. A polyvinyl alcohol binder (Optapix RA 4G, Zimmer \& Schwartz) was dissolved while stirring the solution at $85{ }^{\circ} \mathrm{C}$. The slurry was then cooled to ambient temperature and an antifoaming agent (Contraspum KWE, Zimmer \& Schwartz) was added. Organic polyurethane sponges of 10 ppi (Foam-Partner, Fritz Nauer AG) were then immersed into the slurry. The coated foams were dried in air and finally sintered in an electrically heated furnace (Nabertherm $\mathrm{GmbH}$ ) at $1873 \mathrm{k}$ to remove the organic polyurethane matrix and carbon pore-forming agent particles and sinter the ceramic body. ${ }^{39}$

\section{Characterization}

Sample morphology and interconnectivity of the $\mu \mathrm{m}$-scale pores were analyzed via scanning electron microscopy (SEM, Hitachi
TM-1000 and ESEM XL30 with back-scattered electron detector). Interconnectivity was investigated by penetration of an organic resin into the porous network. Samples were first immersed in organic resin (Araldite BY 158 epoxy mixed with aliphatic polyamine Aradur 21 in a $4: 1 \mathrm{vol}$ ratio) at a total pressure of 25 mbar. Complete penetration of resin into the pores was ensured by subsequent exposure to an overpressure of 2 bar. After hardening, the specimens were polished and a $\mathrm{Pd} / \mathrm{Au}$ sputtering was applied to the surface to ensure electron conductivity during SEM analysis. Pore size distribution and SSA were analyzed using mercury intrusion porosimetry (Quantachrome Poremaster 60-GT, Quantachrome GmbH, Germany) assuming a cylindrical pore model.

\section{Experimental methodology with TGA}

RPC samples were cycled in a thermogravimetric analyzer (TGA, Netzsch STA 409 SD). Samples with a mass of $1158 \pm$ $12 \mathrm{mg}$ were placed on a flat $17 \mathrm{~mm}$ diameter $\mathrm{Al}_{2} \mathrm{O}_{3}$ crucible. Gases were delivered using a mechanical mass flow controller (Voegtlin Q-Flow 140), and gas composition was analyzed by gas chromatography (GC, Varian 490). Thermal reduction was performed at $1773 \mathrm{~K}$ for $30 \mathrm{~min}$ under an Ar atmosphere with a background $p_{\mathrm{O}_{2}}$ of $1.8 \times 10^{-4}$ atm. Ar (99.999\% purity) was

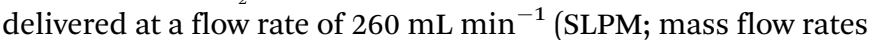
calculated at $273.15 \mathrm{~K}$ and $1 \mathrm{~atm})$. Oxidation with $\mathrm{CO}_{2}(99.995 \%$ purity) was performed at temperatures ranging from 873 to $1273 \mathrm{~K}$ for $60 \mathrm{~min}$. Unless otherwise stated, $160 \mathrm{~mL} \mathrm{~min}^{-1}$ of $\operatorname{Ar}(\mathrm{g})$ and $100 \mathrm{~mL} \mathrm{~min}^{-1}$ of $\mathrm{CO}_{2}(\mathrm{~g})$ were delivered during oxidation, resulting in a $\mathrm{CO}_{2}$ concentration of 0.385 atm inside the TGA furnace. Heating and cooling rates of $20 \mathrm{~K} \mathrm{~min}^{-1}$ were applied in all runs. To account for buoyancy effects, blank runs were performed with an inert $\mathrm{ZrO}_{2}$-made RPC of similar mass to the ceria-made RPC. Residual $\mathrm{O}_{2}$ during oxidation was accounted for by replacing $\mathrm{CO}_{2}$ with $\mathrm{Ar}$ and subtracting the observed mass increase.

\section{Experimental methodology using a solar reactor}

RPC-30 (total mass $=948 \mathrm{~g}$ ) was loaded in a solar cavity-receiver in the form of a cylinder composed of four $20 \mathrm{~mm}$-thick, $60 \mathrm{~mm}$-i.d., $100 \mathrm{~mm}$-o.d. rings, and a single $20 \mathrm{~mm}$-thick, 100 mm-o.d. disk. The solar reactor and peripheries were previously described in detail. ${ }^{22}$ Temperatures were measured at the outer surface of the RPC using B-type thermocouples. Argon (99.999\% purity) and $\mathrm{CO}_{2}$ (99.998\% purity) flow rates were regulated by electronic mass flow controllers (Bronkhorst F-201 C). Product gas composition was monitored by gas chromatography (Varian 490), supplemented by a paramagnetic alternating pressure based $\mathrm{O}_{2}$ detector (Siemens Oxymat 6) and infrared detectors for $\mathrm{CO}$ and $\mathrm{CO}_{2}$ (Siemens Ultrama). Experimentation was carried out at the High-Flux Solar Simulator (HFFSS) of ETH Zurich. An array of seven Xe-arcs, close-coupled to truncated ellipsoidal reflectors, provided an external source of intense thermal radiation that closely approximated the heat transfer characteristics of highly concentrating solar systems. During reduction, the solar power input $\left(P_{\text {solar }}\right)$ was $3.8 \mathrm{~kW}$ and 
the Ar flow rate was $6 \mathrm{~L} \mathrm{~min}{ }^{-1}$. During oxidation $P_{\text {solar }}=0$ and the $\mathrm{CO}_{2}$ flow rate was $6 \mathrm{~L} \mathrm{~min}^{-1}$.

\section{Nomenclature}

\begin{tabular}{|c|c|}
\hline$C_{\mathrm{p}}$ & Heat capacity $\left(\mathrm{J} \mathrm{mol}^{-1} \mathrm{~K}^{-1}\right)$ \\
\hline$d_{\text {mean }}$ & Mean pore size $(\mathrm{m})$ \\
\hline$E_{\mathrm{a}}$ & Apparent activation energy $\left(\mathrm{J} \mathrm{mol}^{-1}\right)$ \\
\hline$E_{\text {inert }}$ & $\begin{array}{l}\text { Energy required to separate the inert gas from the } \\
\text { air }\left(\mathrm{J} \mathrm{mol}^{-1}\right)\end{array}$ \\
\hline$\Delta H_{\mathrm{CO}}$ & Heating value of carbon monoxide $\left(\mathrm{J} \mathrm{mol}^{-1}\right)$ \\
\hline$h_{\mathrm{rxn}}$ & Reaction enthalpy $\left(\mathrm{J} \mathrm{mol}^{-1}\right)$ \\
\hline$P_{\text {solar }}$ & Radiation power input (W) \\
\hline$p$ & Pressure (atm) \\
\hline$p_{\mathrm{O}_{2}}$ & Partial pressure of oxygen (atm) \\
\hline$p_{\mathrm{CO}_{2}}$ & Partial pressure of carbon dioxide (atm) \\
\hline ppi & Pores per inch \\
\hline$r$ & Molar rate $\left(\mathrm{mol} \mathrm{s}^{-1}\right)$ \\
\hline$T$ & Temperature $(\mathrm{K})$ \\
\hline$t$ & Time (s) \\
\hline
\end{tabular}

\section{Greek letters}

$\begin{array}{ll}\delta & \text { Nonstoichiometry } \\ \delta_{\mathrm{i}} & \text { Initial nonstoichiometry } \\ \delta_{\mathrm{f}} & \text { Final nonstoichiometry } \\ \varepsilon_{\text {sample }} & \text { Sample porosity } \\ \varepsilon_{\text {strut }} & \text { Strut porosity } \\ \eta_{\text {solar-to-fuel }} & \text { Solar-to-fuel energy conversion efficiency }\end{array}$

\section{Abbreviations}

$\begin{array}{ll}\text { BET } & \text { Brunauer-Emmett-Teller theory } \\ \text { GC } & \text { Gas chromatography } \\ \text { RPC } & \text { Reticulated porous ceramic } \\ \text { SLPM } & \text { Standard liters per minute, calculated at } 273.15 \mathrm{~K} \\ & \text { and } 1 \text { atm } \\ \text { SEM } & \text { Scanning electron microscope } \\ \text { SSA } & \text { Specific surface area } \\ \text { TGA } & \text { Thermogravimetric analyzer }\end{array}$

\section{Acknowledgements}

Financial support from the Swiss Competence Center Energy \& Mobility and from the European Research Council under the European Union's ERC Advanced Grant (SUNFUELS - no. 320541) is gratefully acknowledged.

\section{References}

1 A. Steinfeld, Sol. Energy, 2005, 78, 603-615.

2 C. Perkins and A. W. Weimer, Int. J. Hydrogen Energy, 2004, 29, 1587-1599.

3 G. P. Smestad and A. Steinfeld, Ind. Eng. Chem. Res., 2012, 51, 11828-11840.
4 C. Graves, S. D. Ebbesen, M. Mogensen and K. S. Lackner, Renewable Sustainable Energy Rev., 2011, 15, 1-23.

5 W. C. Chueh, A. H. McDaniel, M. E. Grass, Y. Hao, N. Jabeen, Z. Liu, S. M. Haile, K. F. McCarty, H. Bluhm and F. El Gabaly, Chem. Mater., 2012, 24, 1876-1882.

6 O. T. Sørensen, J. Solid State Chem., 1976, 18, 217-233.

7 W. C. Chueh and S. M. Haile, Philos. Trans. R. Soc. London, Ser. A, 2010, 368, 3269-3294.

8 M. Zinkevich, D. Djurovic and F. Aldinger, Solid State Ionics, 2006, 177, 989-1001.

9 G. Zhou, P. R. Shah, T. Montini, P. Fornasiero and R. J. Gorte, Surf. Sci., 2007, 601, 2512-2519.

10 R. Bader, L. J. Venstrom, J. H. Davidson and W. Lipiński, Energy Fuels, 2013, 27, 5533-5544.

11 C. L. Muhich, B. W. Evanko, K. C. Weston, P. Lichty, X. Liang, J. Martinek, C. B. Musgrave and A. W. Weimer, Science, 2013, 341, 540-542.

12 Y. Hao, C.-K. Yang and S. M. Haile, Phys. Chem. Chem. Phys., 2013, 15, 17084-17092.

13 M. Roeb, C. Sattler, R. Klüser, N. Monnerie, L. de Oliveira, A. G. Konstandopoulos, C. Agrafiotis, V. T. Zaspalis, L. Nalbandian, A. Steele and P. Stobbe, J. Sol. Energy Eng., 2006, 128, 125.

14 R. B. Diver, J. E. Miller, N. P. Siegel, T. A. Moss, ASME Conference Proceedings, 2010, 2010, 97-104.

15 L. O. Schunk, P. Haeberling, S. Wepf, D. Wuillemin, A. Meier and A. Steinfeld, Trans. ASME: J. Sol. Energy Eng., 2008, 130, 201009.

16 S. Abanades and G. Flamant, Sol. Energy, 2006, 80, 1611-1623.

17 T. Kodama, S.-i. Enomoto, T. Hatamachi and N. Gokon, J. Sol. Energy Eng., 2008, 130, 014504.

18 W. C. Chueh, C. Falter, M. Abbott, D. Scipio, P. Furler, S. M. Haile and A. Steinfeld, Science, 2010, 330, 1797-1801.

19 L. J. Venstrom, N. Petkovich, S. Rudisill, A. Stein and J. H. Davidson, J. Sol. Energy Eng., 2012, 134, 011005.

20 S. G. Rudisill, L. J. Venstrom, N. D. Petkovich, T. Quan, N. Hein, D. B. Boman, J. H. Davidson and A. Stein, J. Phys. Chem. C, 2012, 117, 1692-1700.

21 P. Furler, J. R. Scheffe and A. Steinfeld, Energy Environ. Sci., 2012, 5, 6098.

22 P. Furler, J. R. Scheffe, M. Gorbar, L. Moes, U. Vogt and A. Steinfeld, Energy Fuels, 2012, 26, 7051-7059.

23 N. Gokon, T. Kodama, N. Imaizumi, J. Umeda and T. Seo, Int. J. Hydrogen Energy, 2011, 36, 2014-2028.

24 T. Kodama, T. Hasegawa, A. Nagasaki and N. Gokon, J. Sol. Energy Eng., 2009, 131, 021008.

25 J. F. Muir, R. E. Hogan Jr, R. D. Skocypec and R. Buck, Sol. Energy, 1994, 52, 467-477.

26 N. Siegel, R. Diver, J. E. Miller, T. Garino, S. Livers, ASME Conference Proceedings, 2009, 2009, 431-437.

27 R. J. Panlener, R. N. Blumenthal and J. E. Garnier, J. Phys. Chem. Solids, 1975, 36, 1213-1222.

28 R. B. Diver, J. E. Miller, M. D. Allendorf, N. P. Siegel and R. E. Hogan, J. Sol. Energy Eng., 2008, 130, 041001.

29 J. Lapp, J. H. Davidson and W. Lipiński, J. Sol. Energy Eng., 2013, 135, 031004. 
30 H. Kaneko, T. Miura, A. Fuse, H. Ishihara, S. Taku, H. Fukuzumi, Y. Naganuma and Y. Tamaura, Energy Fuels, 2007, 21, 2287-2293.

31 W. C. Chueh and S. M. Haile, ChemSusChem, 2009, 2, 735-739. 32 M. W. Chase, C. A. Davies, J. R. Downey, D. J. Frurip, R. A. McDonald and A. N. Syverud, Standard Reference Data Program National Institute of Standards and Technology, Gaithersburg, 1986.

33 I. Riess, M. Ricken and J. Noelting, J. Solid State Chem., 1985, 57, 314-322.

34 O. Levenspiel, Chemical Reaction Engineering, John Wiley \& Sons, 3rd edn, 1999.
35 H.-W. Haering, Industrial Gases Processing, Wiley-VCH Verlag GmbH \& Co. KGaA, 2008.

36 S. Haussener, P. Coray, W. Lipinski, P. Wyss and A. Steinfeld, J. Heat Transfer, 2010, 132, 023305.

37 S. Haussener and A. Steinfeld, Materials, 2012, 5, 192-209.

38 K. Schwartzwalder, H. Somers and V. A. Somers, Method of making porous ceramic articles, U. S. P. Office, US, 1963.

39 U. F. Vogt, M. Gorbar, P. Dimopoulos-Eggenschwiler, A. Broenstrup, G. Wagner and P. Colombo, J. Eur. Ceram. Soc., 2010, 30, 3005-3011. 